6. Henry A Spiller, Hannah L Hays, Alfred Aleguas Jr. Overdose of drugs for attentiondeficit hyperactivity disorder: clinical presentation, mechanisms of toxicity, and management. CNS Drugs 2013, 27(7), 531-43.
7. Abubakar II., Tillmann T, Banerjee A et al. Global, regional, and national age-sex specific allcause and cause-specific mortality for 240 causes of death, 1990-2013: a systematic analysis for the Global Burden of Disease Study 2013. Lancet 2015 385(9963), 117-171.

\title{
NGHIÊN CỨU YẾU TỐ LIÊN QUAN ĐẾN TỔN THƯƠNG VÕNG MAC HOÀNG ĐIỂM TRÊN LÂM SÀNG VÀ ĐÔ DÀY VÕNG MẠC HOÀNG ĐIỂM TRÊN OCT Ở MẮT CÂ̂N THỊ CAO
}

\section{TÓM TẮT}

Mục tiêu: Tìm hiểu mối liên quan giữa tổn thương võng mạc hoàng điểm với chỉ số độ dày của vùng võng mạc hoàng điểm trên $\mathrm{OCT}$ ở mắt cân thị cao và tìm hiểu một số yếu tố nguy cơ. Đối tượng và phương pháp nghiên cứu: Nghiên cứu mổ tả cắt ngang trên 168 mắt của 88 bệnh nhân có mức độ cận thị $\leq-6,00 D$, tại khoa Khúc xạ - Bệnh viện Mắt Trung Ương. Kết quả: Tỷ lệ tổn thương võng mạc hoàng điểm $66,1 \%$; trong đó đáy mắt hình khảm 60,7\%; teo hắc võng mạc lan tỏa $4,2 \%$; teo hắc võng mạc dạng mảng $1,2 \%$. Độ dày võng mạc hoàng điểm trung bình là 244,93 $\pm 29,09 \mu \mathrm{m}$, mỏng nhất là $124 \mu \mathrm{m}$, dày nhất là $344 \mu \mathrm{m}$. Độ dày võng mạc vùng hoàng điểm trung tâm và vùng hoàng điểm trên các mắt có tổn thương mỏng hơn so với các mắt không có tổn thương đáy mắt, sự khác biệt có ý nghĩa thổng kê với $\mathrm{p}<0,05$. Các yếu tố nguy cơ có liên quan đến tổn thương võng mạc hoàng điểm: mức độ cận thị càng cao, trục nhãn cầu càng dài, thời gian mắc cận thị càng nhiều, tuổi bệnh nhân càng cao thì nguy cơ tổn thương đáy mắt càng nhiều. Mặc dù có sự mỏng đi của chiêu dày võng mạc vùng hoàng điểm trên các mắt cận thị cao nhưng nghiên cứu không phát hiện thấy mối liên quan giữa độ dày võng mạc vùng hoàng điểm trung bình và các yếu tố khác như tuổi, thời gian mắc cận thị, mức độ cận thị, chiều dài trực nhãn cầu. Kết luận: Chiều dày võ̃ng mạc hoàng điểm trên OCT mỏng hớn ở mắt có tổn thương võng mac hoàng điểm so với mắt không có tổn thương. Mức độ cận thị, chiều dài trực nhãn câu, tuổi và thời gian mắc cận thị là những yểu tố nguy cơ chính gây tổn thương võng mac hoàng điểm.

\section{SUMMARY}

STUDYING FACTORS RELATED TO THE MACULAR RETINAL CHANGES IN CLINIC AND THE MACULAR RETINAL THICKNESS BY OCT IN HIGH MYOPIC EYES

${ }^{1}$ BV Mắt trung ương

Chịu trách nhiệm chính: Nguyễn Thị Thu Hiền

Email: Thuhienvnio@gmail.com

Ngày nhận bài: 24.2.2021

Ngày phản biên khoa hoc: 5.4.2021

Ngày duyệt bài: 14.4 .2014
Nguyễn Thị Thu Hiền'1, Phạm Thị Minh Châu ${ }^{1}$

Objective: To find out the relationship between macular retinal changes with the macular retinal thickness by OCT in high myopia and some risk factors. Methods: A cross-sectional study on 168 eyes of 88 patients with high myopia was conducted between January 2020 and August 2020 at the Refraction Department of Vietnam National Institute of Ophthalmology. Data collected included history related to myopia progression and macular zone, macular thickness in OCT. Results: The maculopathy $66.1 \%$, tessellated fundus $60.7 \%$, diffuse choroiretinal atrophy $4.2 \%$, patchy choroiretinal atrophy $1.2 \%$. Macular thickness average was $244.93 \pm 29.09 \mu \mathrm{m}$, thinnest was $124 \mu \mathrm{m}$ and thicknest was $344 \mu \mathrm{m}$. Macular thickness in tessellated fundus, diffuse choroiretinal atrophy were thinner than patchy choroiretinal atrophy. The risk factors of myopiarelated retinal changes: high power of myopic, longer axial length, duration of myopia and age of patients related to myopic maculopathy. But no evidence of these risk factors related with macular thickness in OCT despite of thinner of macular thickness in high myopia patients. Conclusions: The thickness of macular retinal by OCT in the eyes with macular retinal changes is thinner. Myopic level, axial length, age and duration of myopia were the risk factors of myopia-related retinal changes.

\section{I. ĐĂT VẤN ĐỀ}

Cận thị, đặc biệt cận thị cao là tật khúc xạ phổ biến hiện nay, gây ảnh hưởng chủ yếu đến thị lực, làm suy giảm chất lượng cuộc sống đồng thời gây ra gánh nặng kinh tế đáng kể cho cá nhân và toàn xã hội. Theo Tổ chức y tế thế giới dự đoán đến năm 2050, tỷ lệ cận thị có thể đến $52 \%$ dân số thế giới (khoảng 5 tỷ người), trong đó cận thị cao chiếm $10 \%{ }^{1}$. Cận thị cao do sự kéo dài trục nhãn cầu và liên quan đến sư thay đổi cấu trúc của protein collagen, có thể dẩn đến những thay đổi thoái hóa và mỏng của võng mạc, hắc mạc và củng mạc. Với việc tích hợp các kỹ thuật mới như chụp cắt lớp võng mạc quang học OCT (optical coherence tomography) giúp hố trợ các bác sỹ nhãn khoa trong việc phát hiện, theo dõi và định hướng điều trị các tổn thương 
tại đáy mắt trên các mắt cận thị cao². Chỉ có OCT với độ phân giải cao và nhiều lớp cắt mới có thể xác định được độ dày của võng mạc vùng hoàng điểm. Trên thế giới và tai Viêt Nam, đã có một số nghiên cứu về đặc điểm tổn thương trên OCT của các mắt có bệnh võng mạc ${ }^{3}$ do cận thị cao. Nhưng các nghiên cứu chưa đề cập đển các chỉ số chiều dày của võng mạc vùng hoàng điểm trên các mắt cận thị cao có hoặc không có tổn thương. Vì vậy chúng tôi thực hiện đề tài này nhằm mục tiêu: Tìm hiểu mối liên quan giữa tổn thương võng mạc hoàng điểm với chỉ số độ dày của vùng võng mạc hoàng điểm trên OCT ở mắt cận thị cao và một số yếu tố nguy cơ.

\section{II. ĐỐI TƯƠNG VÀ PHƯƠNG PHÁP NGHIÊN CỨU}

2.1. Đối tượng nghiên cứu. Bệnh nhân từ 12 tuổi trở lên, được chẩn đoán cận thị từ $6,00 \mathrm{D}$ trở lên sau soi bóng đồng tử có tra thuốc liệt điều tiết, ở một hoặc hai mắt, có hoặc không kèm loạn thị, khám tại khoa Khúc xạ - Bệnh viện mắt Trung ương từ tháng 01/2020 đến tháng 08/2020.

Loai trừ: bệnh nhân có các bênh lý toàn thân có biểu hiện tại mắt, tiền sử chẩn thương, phẫu thuật nội nhãn, tiền sử bệnh võng mạc trẻ đẻ non. Bệnh nhân có bệnh lý tại mắt: đục môi trường trong suốt, bệnh lý võng mạc khổng do cận, glocom, bệnh lý thị thần kinh.

\subsection{Phương pháp nghiên cứu}

Thiết kế nghiên cứu: mô tả cắt ngang

Cõ̃ mẫu nghiên cứu: 168 mắt của 88 bệnh nhân

Qui trinh nghiên cứu:

Bảng 3.1. Tỷ lệ tổn thương vông mạc hoàng điểm (VMHĐ) trên lâm sàng và các chỉ số chiều dày vống mạc hoàng điểm tương ứng trên OCT

\begin{tabular}{|c|c|c|c|c|}
\hline \multicolumn{2}{|c|}{ Tổn thương VMHĐ } & $n, \%$ & $\begin{array}{l}\text { Chiều dày HĐ trung } \\
\text { tâm trung bình }(\mu \mathrm{m})\end{array}$ & $\begin{array}{l}\text { Chiều dày HÐ } \\
\text { trung bình }(\mu \mathrm{m})\end{array}$ \\
\hline \multicolumn{2}{|r|}{ Không tổn thương } & $57(33,9 \%)$ & $243,95 \pm 24,45$ & $243,95 \pm 24,45$ \\
\hline \multirow{4}{*}{$\begin{array}{l}\text { Có tổn } \\
\text { thương }\end{array}$} & ก́́m móthinh & 102 & & $262,39 \pm 16,68$ \\
\hline & Teo & 7 & & \\
\hline & Teo hắc võng mạc dạ & 2 & $291,00 \pm 24,04$ & $273,00 \pm 4,24$ \\
\hline & Chung & $111(66,1 \%)$ & $245,44 \pm 31,30$ & $261,98 \pm 17,24$ \\
\hline & $168(100 \%)$ & $244,93 \pm 29,09$ & $264,72 \pm 16,11$ \\
\hline
\end{tabular}

Tổng số mắt không có tổn thương võng mạc hoàng điểm là 57 mắt $(33,9 \%)$, ít hơn số mắt có tổn thương là $111(66,1 \%)$, sự khác biệt có ý nghĩa thống kê $(p<0,01)$. Tổn thương đáy mắt hình khảm có 102 mắt $(60,7 \%)$, teo hắc võng mạc lan tỏa có 7 mắt $(4,2 \%)$, teo hắc võng mạc dạng mảng có 2 mắt $(1,2 \%)$, không có mắt nào có teo hoàng điểm. Tuy nhiên kết quả của chúng tôi thấp hơn so với nghiên cứu của Koh $(2013)^{4}$
- Hỏi bệnh: xác định thời điểm cận, thời gian cận, tiền sử gia đình, cũng như loại trừ các bệnh lý tại mắt và toàn thân không phù hợp với nghiên cứu.

- Soi bóng đồng tử sau nhỏ thuốc liệt điều tiết Cyclogyl $1 \%$ để xác định tình trạng khúc xạ

- Khám nhãn cầu bằng sinh hiển vi khám để đánh giá tình trạng bán phần trước và tình trạng dịch kính, gai thị, võng mạc trung tâm, võ̃ng mạc chu biên.

- Siêu âm nhãn cầu: đánh giá tình trạng dịch kính, võng mạc và chiều dài trục nhãn cầu.

- Chụp OCT với đồng tử giãn tối đa: Phần võng mạc hậu cực, lấy các chỉ số chiêu dày võng mạc hoàng điểm và chiều dày võng mạc hoàng điểm trung tâm.

Xử lí số liệu: số liệu được thu thập và xử lí bằng phần mểm SPSS 22.

\section{KẾT QUẢ NGHIÊN CỨU VÀ BÀN LUÂ̂N}

3.1. Mối liên quan giữa tổn thương võng mạc hoàng điểm trên lâm sang với chỉ số độ dày của võng mạc hoàng điểm trên OCT ở mắt cận thị cao. Trên mắt cận thị cao, trục nhãn cầu từ trước ra sau thường dài quá mức, làm co kéo, giãn lồi củng mạc, dẩn đến giảm độ dày và làm thay đổi cấu trúc giải phẩu bình thường. Do đó thiếu cung cấp oxy và chất dinh dưỡng, gây ra hàng loạt biến đổi, tình trạng thoái hoá ở hắc võng mạc, dịch kính và gây giảm thị lực.

Mức độ cận thị trung bình trong nghiên cứu của chúng tôi là $-8,75 \pm 2,61 \mathrm{D}$, đây là mức cận thị cao, do đó dễ dẫn đến tổn thương ở võng mạc hoàng điểm. đưa ra: tỷ lệ thoái hóa võng mạc hoàng điểm tới $85,7 \%$ và cao hơn nghiên cứu của Xiao $(2018)^{5}$ đưa ra: tỷ lệ tổn thương VMHĐ là $43 \%$, trong đó tỷ lệ tổn thương đáy mắt hình khảm chiếm $20,0 \%$; teo hắc võng mạc lan tỏa chiếm $20,2 \%$; teo hắc võng mạc dạng mảng chiếm $2,6 \%$; teo hoàng điểm chiểm $0,2 \%$. Điều này có thể được giải thích là trong nghiên cứu của $K^{4}{ }^{4}$, tác giả chọn những bệnh nhân có độ tuổi từ 18 và độ 
cân từ $-10,00 \mathrm{D}$ trở lên, cao hơn trong nghiên cứu của chúng tôi nên số bệnh nhân có tỷ lệ tổn thương võng mạc hoàng điểm nhiều hơn.

Độ dày võng mạc vùng hoàng điểm trung bình là 244,93 $\pm 29,09 \mu \mathrm{m}$, trong đó mỏng nhất là $124 \mu \mathrm{m}$, dày nhất là $344 \mu \mathrm{m}$. Trong nghiên cứu không có trường hợp mắt cận thị cao nào có tân mạch dưới võng mạc gây võ̃ng mạc hoàng điểm phù hoặc teo. Theo bảng 3.1, độ dày võng mạc vùng hoàng điểm trung tâm và độ dày võng mạc hoàng điểm trên các mắt có tổn thương mỏng hơn so với các mắt không có tổn thương đáy mắt trên lâm sàng, sự khác biệt có ý nghĩa thống kê với $p<0,05$. Một nghiên cứu của Chen (2014) ${ }^{3}$ trên 194 mắt của bệnh nhân từ 6 đến 17 tuổi đã chỉ ra rằng độ dày vùng võng mạc hoàng điểm trung bình trên OCT ở mắt cận thị cao mỏng hơn so với mắt không cận thị và mắt cận thị thấp.

Theo biểu đồ 3.1, với các tổn thương võng mạc hình khảm, teo hắc võng mạc tỏa lan thì chiều dày võng mạc vùng hoàng điểm trung tâm mỏng hơn chiều dày võng mạc vùng hoàng điểm, ngược lại với tổn thương teo hắc võng mạc dạng mảng. Tuy nhiên, sự khác biệt không có ý nghĩa thống kê.

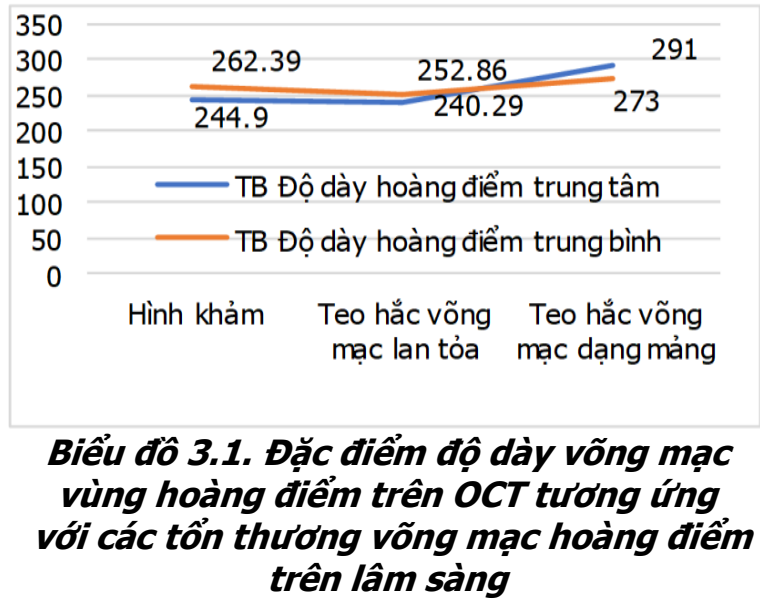

\subsection{Một số yếu tố liên quan đến tổn thương võng mạc hoàng điểm và độ dày võng mạc hoàng điểm trên OCT.}

3.2.1. Mốt số yếu tố liên quan tổn thương vông mạc hoàng điểm

Bảng 3.2 Liên quan giữa các tổn thương vông mạc hoàng điểm với một số yêu tố

\begin{tabular}{|c|c|c|c|c|c|c|}
\hline \multicolumn{2}{|r|}{ Tổn thương } & \multirow{2}{*}{$\begin{array}{l}\text { Không } \\
\text { tổn } \\
\text { thướng }\end{array}$} & \multicolumn{3}{|c|}{ Có tốn thương } & \multirow[b]{2}{*}{ Tổng } \\
\hline \multicolumn{2}{|l|}{$\begin{array}{l}\text { Yêu tô } \\
\text { liên quan }\end{array}$} & & $\begin{array}{l}\text { Hình } \\
\text { khảm }\end{array}$ & $\begin{array}{c}\text { Teo hắc võng } \\
\text { mạc lan tỏa }\end{array}$ & $\begin{array}{c}\text { Teo hắc võng } \\
\text { mạc dạng mảng }\end{array}$ & \\
\hline \multirow{3}{*}{$\begin{array}{l}\text { Mức độ } \\
\text { cận thị }\end{array}$} & Từ -6,00D đến -8,75D & 46 & 58 & 0 & 0 & 104 \\
\hline & Từ $-9,00 \mathrm{D}$ đến $-11,75 \mathrm{D}$ & 11 & 37 & 0 & 0 & 48 \\
\hline & Trên $-12,00 \mathrm{D}$ & 0 & 7 & 7 & 2 & 16 \\
\hline \multirow{4}{*}{$\begin{array}{l}\text { Thời gian } \\
\text { mắc cận thị }\end{array}$} & Từ 1- 5 năm & 14 & 7 & 0 & 0 & 21 \\
\hline & từ 6 - 10 năm & 23 & 45 & 0 & 0 & 68 \\
\hline & từ $11-15$ năm & 18 & 36 & 2 & 0 & 56 \\
\hline & trên 16 năm & 2 & 14 & 5 & 2 & 23 \\
\hline \multirow{4}{*}{ Độ tuô̂i } & Từ $12-<20$ tuối & 42 & 66 & 2 & 0 & 110 \\
\hline & Từ $20-<30$ tuổi & 15 & 20 & 2 & 0 & 37 \\
\hline & Từ 30-<40 tuổi & 0 & 14 & 2 & 0 & 16 \\
\hline & $>40$ tuối & 0 & 2 & 1 & 2 & 5 \\
\hline \multirow{3}{*}{$\begin{array}{l}\text { Chiều dài } \\
\text { trục nhãn } \\
\text { câuu }\end{array}$} & Từ $24-<26 \mathrm{~mm}$ & 13 & 8 & 0 & 0 & 21 \\
\hline & Từ $26-<28 \mathrm{~mm}$ & 35 & 64 & 0 & 0 & 99 \\
\hline & $>28 \mathrm{~mm}$ & 9 & 30 & 7 & 2 & 48 \\
\hline
\end{tabular}

Theo các bảng 3.2, cả 4 yếu tố: tuối, thời gian mắc cận thị, mức độ cận thị và chiều dài trục nhãn cầu, giữa nhóm có tổn thương và không có tổn thương võng mac hoàng điểm khác biệt có ý nghĩa thống kê. Đồng thời qua tính tỉ suất chênh $\mathrm{OR}$ cũng khẳng định có mối liên quan giữa 4 yếu tố trên và tổn thương võng mạc hoàng điểm. Khi tuổi càng tăng, thời gian cận thị càng lâu, mức độ cận thị càng cao và chiều dài trục nhãn cầu càng dài thì càng có nguy cơ tổn thương võng mạc hoàng điểm. Điêuu này có thể giải thích là do những tổn thương ở võng mạc hoàng điểm có nguyên nhân chủ yếu khi trục nhãn cầu kéo dài gây giảm sản biểu mô sắc tố và những biến đổi ở mạch máu hắc võng mạc, từ đó gây những biến đổi ở võng mạc hoàng điểm. Các biến đổi đó tiến triển từ từ theo thời gian, cùng với độ tuổi ngày càng tăng, thời gian mắc cận thị càng lâu, mức độ tật khúc xạ và chiều dài trục nhãn câu cũng càng tằng thì càng có nguy cơ gây tổn thương võng mạc hoàng điểm.

Kết quả này cũng tương tự với một số nghiên 
cứu trên thế giới, Xiao và cộng sự $(2018)^{5}$ nghiên cứu trên 890 bệnh nhân cận thị cao từ $6,00 \mathrm{D}$ trở lên có tuổi trung bình là 19, đã đưa ra kết luận rằng tuổi càng cao, mức độ cận càng tăng, chiều dài trục nhãn cầu càng dài có liên quan với tổn thương ở võng mạc hoàng điểm. Một nghiên cứu khác của Fang $(2018)^{6}$ trên 810 mắt của 432 bệnh nhân cận thị cao từ $-6,00 \mathrm{D}$ trở lên đã khẳng định rằng yểu tố nguy cơ chính dẫn đến sự tiến triển những tổn tương võng mạc hoàng điểm là tuổi lớn hơn và chiều dài trục nhãn câu dài hơn. Tại Trung Quốc, Yan và cộng sư (2018) khi theo dõi tiến triển của tổn thương võ̃ng mạc hoàng điểm ở bệnh nhân cận thị cao trong vòng 10 năm từ 2001 đến 2011, cũng đưa ra kết luận tuổi càng cao, trục nhãn cầu càng dài thì càng có nguy cơ tổn thương võng mạc hoàng điểm. Một nghiên cứu nữa của Cheng (2013) ${ }^{8}$ trên bệnh nhân cận thị cao từ 12 đến 18 tuổi cũng cho rằng khi chiều dài trục nhãn cầu từ $26,5 \mathrm{~mm}$ trở lên có nguy cơ tổn thương võng mạc hoàng điểm.

\subsubsection{Một số yếu tố liên quan tổn} thương vông mạc hoàng điểm

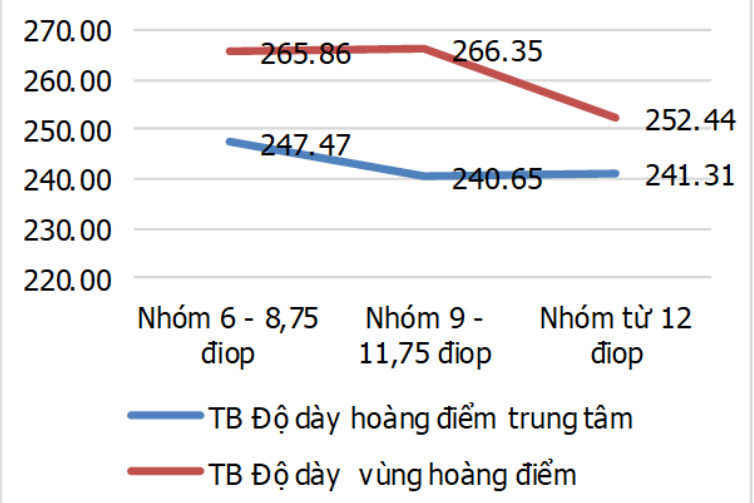

\section{Biểu đồ 3.2. Độ dày VM HĐ trên OCT và mức độ cân cao}

Trong nghiên cứu của chúng tôi không phát hiện thấy mối liên quan giữa độ dày trung bình vùng hoàng điểm và các yếu tố khác như tuổi, thời gian mắc cận thị, tiền sử gia đình, mức độ cận thị, chiều dài trục nhãn câu (biểu đồ 3.2, 3.3,3.4,3.5).

Điêu này có thể giải thích là do khi trục nhãn cầu dài ra ở bênh nhân cận thị cao, sẽ tạo thành những biến đổi ở vùng võ̃ng mạc yếu trước như vùng quanh gai thị, võng mạc chu biên, dần dần mới dân đến những tổn thương ở vùng võng mạc hoàng điểm. Ngoài ra đa số bệnh nhân trong nghiên cứu đều ở lứa tuổi khá trẻ, thời gian mắc cận thị chưa quá dài nên chưa thấy tổn thương độ dày trung bình vùng hoàng điểm trên OCT. Điêu này cũng tương tự với nghiên cứu của Chen (2014) ${ }^{3}$ cũng chỉ ra rằng không có mối liên quan giữa độ dày vùng hoàng điểm với mức độ cận thị, tuổi,...

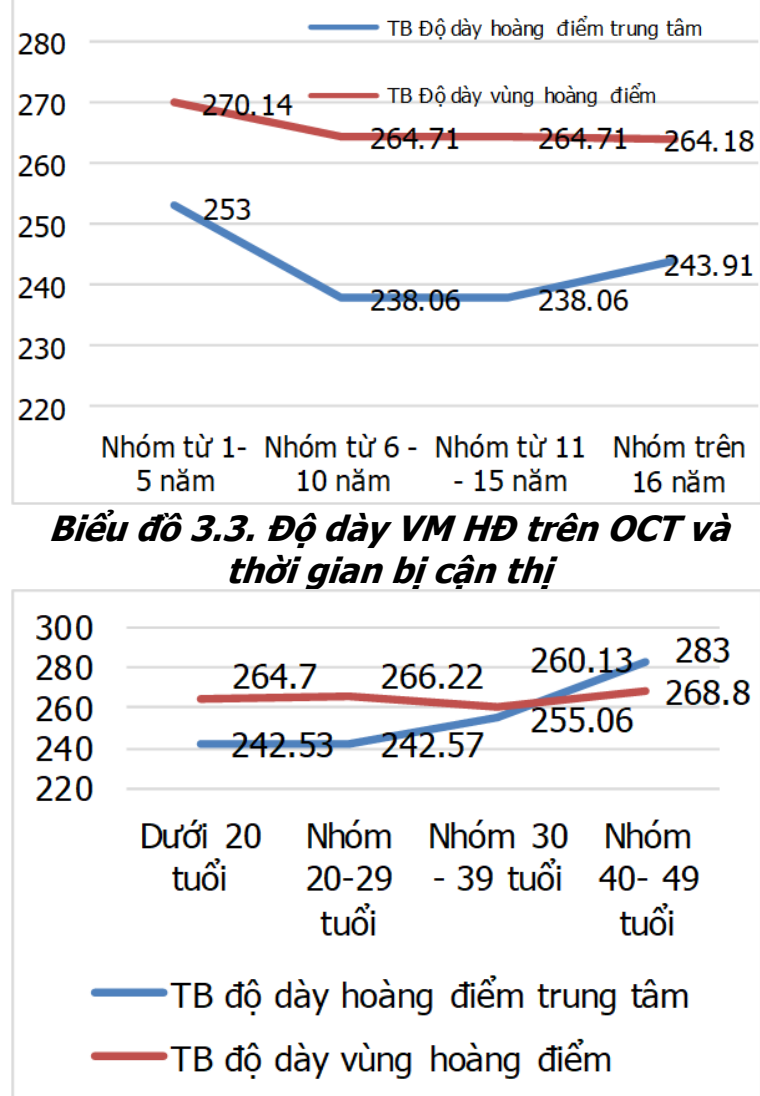

Biểu đồ 3.4. Đặc điểm chiều dày VM vùng hoàng điểm trên OCT với tuổi bệnh nhân

$$
\begin{aligned}
& \begin{array}{llll}
280 & 264.72 & 266.81 & 260.4 \\
260 &
\end{array}
\end{aligned}
$$

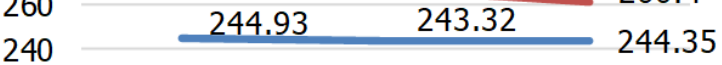

$$
\begin{aligned}
& 220 \\
& \text { Trục NC dưới Trục NC 26- Trục NC trên } \\
& 26 \mu \mathrm{m} \quad 28 \mu \mathrm{m} \quad 28 \mu \mathrm{m} \\
& \text { —TB độ dày hoàng điểm trung tâm } \\
& \text { —TB độ dày vùng hoàng điểm }
\end{aligned}
$$

Biểu đồ 3.5. Đăc điểm chiều dày VM vùng hoàng điểm trên OCT với trục NC

\section{KẾT LUÂ̂N}

Cận thị cao gây ra nhiều tổn thương võng mạc hoàng điểm trên lâm sàng và giảm chiều dày võng mạc vùng hoàng điểm. Chiều dày võng 
mac hoàng điểm trên OCT mỏng hơn ở mắt có tổn thương võng mạc hoàng điểm so với mắt không có tổn thương. Mức độ cận thị, chiều dài trục nhãn cầu, tuổi và thời gian mắc cận thị là những yếu tố nguy cơ chính gây tổn thương võng mạc hoàng điểm trên lâm sàng.

\section{TÀI LIÊU THAM KHẢO}

1. Holden BA, Fricke TR, Wilson DA, et al. Global Prevalence of Myopia and High Myopia and Temporal Trends from 2000 through 2050. Ophthalmology. 2016;123(5):1036-1042.

2. Ng DS, Cheung CYL, Luk FO, Lai TYY et al. Advances of optical coherence tomography in myopia and pathologic myopia, Eye (Lond). (2016) Jul;30(7):901-16.

3. Chen $S$, Wang $B$, Dong $N$, Ren $X$, Zhang $T$, Xiao L. Macular measurements using spectraldomain optical coherence tomography in Chinese myopic children. Invest Ophthalmol Vis Sci. 2014:55(11):7410-7416.

4. Koh VT, Nah GK, Chang $L$, et al. Pathologic changes in highly myopic eyes of young males in Singapore. Ann Acad Med Singapore. 2013;42(5):216-224.

5. Xiao O, Guo $X$, Wang $D$, et al. Distribution and Severity of Myopic Maculopathy Among Highly Myopic Eyes. Invest Ophthalmol Vis Sci. 2018;59(12):4880-4885.

6. Fang $Y$, Yokoi $T$, Nagaoka $\mathbf{N}$, et al. Progression of Myopic Maculopathy during 18-Year Follow-up. Ophthalmology. 2018;125(6):863-877.

7. Yan $\mathbf{Y N}$, Wang $\mathbf{Y X}$, Yang $\mathbf{Y}$, et al. Ten-Year Progression of Myopic Maculopathy: The Beijing Eye Study 2001-2011. Ophthalmology. 2018;125(8):1253-1263.

8. Cheng SC, Lam CS, Yap MK. Prevalence of myopia-related retinal changes among 12-18 year old Hong Kong Chinese high myopes. Ophthalmic Physiol Opt. 2013;33(6):652-660.

\section{NGHIÊN CỨU ỨNG DUUNG PHẪU THUÂT BRICKER ĐIỀU TRI UNG THƯ BẰNG QUANG TẠI BỆNH VIỆN K}

\section{TÓM TẮT}

Muc tiêu: Đánh giá kết quả sớm phẫu thuật bricker điều trị ung thư bàng quang tại bệnh viện $\mathrm{K}$. Đối tượng và phương pháp nghiên cứu: Nghiên cứu can thiêp lâm sàng không đối chứng tiến hành trên các bệnh nhân ung thư biểu mổ bàng quang đã được phẫu thuât cắt bàng quang toàn bô và chuyển lưu dòng tiểu theo phương pháp Bricker tại Bệnh viện $K$, thời gian từ tháng $1 / 2018$ đến $03 / 2020$. Kết quả: 31 bệnh nhân có thời gian phẫu thuật trung bình là $192,25 \pm 33,75$; Biến chứng hay gặ nhất sau phẫu thuật là nhiếm trùng vết mổ $12,8 \%$; bán tắc ruột $6,4 \%$ ngoài ra các biến chứng khác như chảy máu sau mổ, tắc ruột, rò nước tiểu, rò tiêu hóa, bục vết mổ, áp xe cũng gắp với tỉ lê thấp $3,2 \%$. Thới gian nằm viên trung bình 18,00 \pm 8,91ngày. Giải phẫu bệnh diện cắt sau mổ đều âm tính. Kết luận: Phẫu thuật cắt bàng quang toàn bộ theo phương pháp Bricker an toàn về ngoại khoa và đảm bảo nguyên tắc ung thư điều trị triệt căn cho bệnh nhân ung thư bàng quang xâm lấn cơ.

Tư khóa: Ung thư bàng quang.

\section{SUMMARY}

\section{APPLICATION OF BRICKER SURGERY IN THE TREATMENT OF BLADDER CANCER AT K HOSPITAL}

\footnotetext{
*Bênh viện K

Chiu trách nhiệm chính: Phạm Văn Bình

Email: binhva@yahoo.fr

Ngày nhận bài: 19.2.2021

Ngày phản biên khoa học: 29.3.2021

Ngày duyệt bài: 7.4.2021
}

\section{Phạm Văn Bình*, Đỗ Anh Tuấn*}

Purpose: Evaluating the initial outcome of Bricker surgery in the treatment of bladder cancer at $\mathrm{K}$ Hospital. Object and method: An uncontrolled clinical intervention study was conducted on bladder cancer who had received total resection and urinary flow circulation by Bricker technique at $\mathrm{K}$ hospital from January 2018 to March 2020. Results: 31 patients, average surgery time was $192.25 \pm 33.75$. The most common complication after surgery is wound infection 12.8\%; 6,4\% semi-intestinal obstruction. Besides, other complications such as postoperative bleeding, intestinal obstruction, urine leakage, gastrointestinal fistula, incision puncture, abscess also met with a low rate of $3.2 \%$. The average hospital stay time was $18.00 \pm 8.91$. All of the patients had negative surgical margin. Conclusion: Radical cystectomy with Bricker-type urinary diversion is a feasible surgery that guarantees radical treatment for patients with muscle-invasive bladder cancer

Keywords; Bladder cancer.

\section{I. ĐẶT VẤN ĐỀ}

Trong hệ tiết niệu, bàng quang là cơ quan có chức năng chứa và điều hòa bài xuất nước tiểu và có ảnh hưởng lớn tới chất lượng cuộc sông. Theo số liệu thống kê của Bray F. (Globocan 2018), tại Việt Nam, ung thư bàng quang (UTBQ ) đứng hàng thứ hai trong số các ung thư hê tiết niêu. Mỗi năm có 1.502 ca mới mắc và 883 ca tử vong do UTBQ [1],[2].

Với UTBQ xâm lấn, phâuu thuật cắt bàng quang kèm nạo vét hạch vùng là phương pháp 